Gramáticas de la (¿post?) violencia:

identidades, guerras, cuerpos y fronteras

\title{
Los pueblos del campo y los desafíos alrededor de la justicia transicional en Brasil
}

\author{
Adriana Rodrigues Novais ${ }^{1}$ \\ ' Universidade Estadual de Campinas, Campinas/SP, Brasil
}

\section{Resumen}

La Comisión Nacional de la Verdad, constituida por el Gobierno Federal brasileño en 2012, abrió un nuevo campo de disputas en torno de la Memoria, Verdad y Justicia sobre el período de la dictadura cívico-militar (1964-1988). Esto se debió a la entrada en escena de nuevos sujetos, principalmente campesinos e indígenas, quienes, a lo largo del período de redemocratización, habían consolidado, por medio de diversas luchas, su organización político-institucional, un mayor reconocimiento público y la conquista de algunos derechos y políticas sociales. Sin embargo, el ingreso de estos nuevos actores generó resistencias, incluso de sujetos que habían protagonizado hasta ese momento el debate público sobre memoria acerca de la dictadura. Esto pone en evidencia los límites de la llamada Justicia Transicional, tanto desde el punto de vista conceptual y jurídico, como desde el enfoque del imaginario social, de las contradicciones de clase y cultura, de la división entre lo rural y lo urbano, entre otros factores. Este artículo tiene como objetivo debatir sobre la estructura conceptual y normativa que establece criterios para definir a las víctimas como "muertos y desaparecidos políticos", que al mismo tiempo no aplican para otras víctimas. Esta reflexión se basa en el informe producido por la Comisión Nacional de la Verdad, que será comparado tanto con lo que fue producido por la Comisión Campesina de la Verdad, así como con los informes producidos por pueblos indígenas, especialmente, el informe sobre el pueblo Waimiri-Atrori. Por lo tanto, el proceso de comprensión, reflexivo-analítico, se propone pensar tanto los sentidos de la disputa por la Memoria, Verdad y Justicia en nuestros días, en un contexto de violencia continuada, como los desdoblamientos de dicha disputa para los pueblos del campo.

Palabras clave: Justicia Transicional; Pueblos del campo; Muertos y desaparecidos; Dictadura cívico-militar. 


\section{Os povos do campo e os desafios em torno da justiça de transição no Brasil}

\section{Resumo}

Ao ser constituída pelo Governo Federal, em 2012, a Comissão Nacional da Verdade abriu um novo campo de disputas em torno da Memória, Verdade e Justiça, sobre o período da ditadura civil-militar (1964-1988), principalmente em função da entrada de novos sujeitos em cena, particularmente camponeses e indígenas que, ao longo do período de redemocratização, haviam consolidado sua organização político-institucional, reconhecimento público e conquista de alguns direitos e políticas sociais por meio de inúmeras lutas. A entrada desses novos sujeitos, porém, não ocorreu sem resistências - inclusive de outros sujeitos que protagonizaram o debate público sobre memória da ditadura até aquele momento, colocando em evidência os limites da Justiça de Transição, tanto do ponto de vista conceitual e jurídico, quanto do ponto de vista do imaginário social, das contradições de classe e de cultura, do corte rural e urbano, entre outras. Esse artigo tem como objetivo debater sobre o arcabouço conceitual e normativo que estabelece os critérios que qualifica as vítimas como "mortos e desaparecidos políticos", ao mesmo tempo em que esse lugar não cabe a outras tantas vítimas. Essa reflexão tomará como base o relatório produzido pela Comissão Nacional da Verdade, comparado com o que foi produzido pela Comissão Camponesa da Verdade e com os relatórios produzidos pelos povos indígenas, especialmente o relatório sobre o povo Waimiri-Atroari. Esse processo de compreensão reflexivo-analítico se realiza para, então, pensar os sentidos desta luta por Memória, Verdade e Justiça nos dias atuais, no contexto de violência continuada, e os desdobramentos dessa luta para os povos do campo.

Palavras-chave: Justiça de Transição; Povos do campo; Mortos e Desparecidos; Ditadura civil-militar. 


\title{
Los pueblos del campo y los desafíos alrededor de la justicia transicional en Brasil
}

\author{
Adriana Rodrigues Novais
}

\section{Introducción}

Comparado con los demás países Sudamericanos, Brasil presenta una mayor dificultad para lidiar con el pasado referido a la dictadura cívico-militar (1964-1985); fue también el último en crear una Comisión de la Verdad. Además, sus políticas para la valorización de la memoria de las víctimas y su reparación económica están marcadas por fragmentaciones y discontinuidades. Desde el punto de vista de las responsabilidades de los crímenes durante ese período, no hubo condenas que terminaran en prisión ${ }^{1}$, lo que representa un atraso en lo que Ruth Teitel (2003) ha llamado como Justicia Transicional (JT)2. A pesar de su amplio desarrollo, existe una extensa literatura que destaca las limitaciones de la Justicia Transicional en diversas situaciones (Le Franc \& Mouralis, 2014).

Las comisiones de la Verdad son instrumentos de la Justicia Transicional que tienen como objetivo esclarecer los acontecimientos pasados y garantizar que las memorias de las víctimas también puedan circular; es decir, buscan expresar simbólicamente la constitución de un nuevo orden político, que prioriza el respeto a los derechos humanos y se compromete con los valores democráticos, negando las guerras y las políticas autoritarias. Estas comisiones no son órganos jurisdiccionales, ni tampoco tienen el propósito de sustituirlos. Sin embargo, pueden recomendar amnistías, juicios, entre otras medidas, que dependen de las potestades que se les atribuyan (Pinto, 2010; Weichert, 2011). También poseen una dinámica propia de funcionamiento, y aunque no tienen una forma única de actuación, todas ellas tienen un período determinado para realizar sus trabajos, que concluyen con un informe final (Pinto, 2010). La efectividad de la justicia de transición dependerá de las características políticas y sociales de cada país (Brito et al, 2004).

En Brasil, las luchas por el derecho a la Memoria, la Verdad y la Justicia de muchas(os) militantes de derechos humanos, de Familiares de los Muertos y Desaparecidos Políticos y diversas entidades construidas desde los últimos años de dictadura (Teles, 2001), derivaron en la Comisión Nacional de la Verdad (CNV), instituida en 2012 por la Ley no 12.528 del 18 de noviembre de 2011,

Art. 1. Con la finalidad de examinar y esclarecer las graves violaciones de derechos humanos realizadas en el período fijado en el art. 8o del Acto de las Disposiciones Constitucionales Transitorias [1946-1988], con el fin de hacer efectivo el derecho a la memoria y la verdad histórica y promover la reconciliación nacional (Brasil, 2011). ${ }^{3}$

\footnotetext{
El único caso de condena fue el del ex coronel del Ejército Carlos Alberto Brilhante Ustra, acusado de torturar a presos políticos en la década de 197o; pero no llegó a ser detenido.

2 La Justicia Transicional puede ser definida como un conjunto de medidas en respuesta a las violaciones sistemáticas de derechos humanos perpetradas en períodos de guerras y gobiernos autoritarios. Su marco inicial fue el Tribunal de Nüremberg, instituido después de la Segunda Guerra Mundial. Desde esta justicia se busca reconocimiento para las víctimas y la promoción de posibilidades para la paz, la reconciliación y la democracia (ICTJ On line).
} 
Este paso importante en la revisión de la historia reciente, aunque tardío, fue un punto de inflexión para que diversos movimientos iniciaran en Brasil lo que se dio en llamar la lucha por la Memoria, la Verdad y por la Justica (MJV), otorgando significados locales a conceptos muy extendidos en el campo internacional de los derechos humanos.

Como se ha mencionado, las características de las comisiones están dadas por las contingencias políticas y sociales de los distintos países. Su duración, en América Latina, ha ido desde los 3 meses, como en Ecuador, hasta los 3 años, como en el caso de Bolivia. La Comisión de la Verdad de Brasil tuvo una duración de 2 años y 6 meses. Entre las particularidades de la realidad brasileña, destaco la intensa movilización de entidades e instituciones de todo el país, que reconocieron en ese momento una oportunidad singular para fortalecer las dimensiones de la lucha que englobaron, en los conceptos de Memoria, Verdad y Justicia. Así, se conformaron en todos los estados brasileños comisiones y/o comités -que llevaban en sus nombres esas tres palabras: Memoria, Verdad y Justicia- con el objetivo de contribuir con la Comisión Nacional de la Verdad (CNV) recién instalada, proceso que fue más allá de los trabajos de la CNV y se ha prolongado hasta estos días. ${ }^{4}$

Desde la construcción del Plan Nacional de Derechos Humanos, en 2009, que preveía la creación de una Comisión de la Verdad, hasta la entrega de su informe final, en diciembre de 2014, ocurrieron disputas en el ámbito del Estado, ${ }^{5}$ así como en diversos segmentos de la sociedad civil y entre los grupos de víctimas. En este artículo voy a detenerme específicamente en las leyes ya constituidas, sus alcances y en la gramática normativa que orienta los instrumentos de la Justicia Transicional en Brasil, incluída la propia CNV.

Las contradicciones se expresaron, por ejemplo, en un contingente de víctimas no reconocidas, a saber: los campesinos, los pueblos indígenas, los sujetos LGBTs, los trabajadores, entre otros, cuyas violaciones sufridas y sus experiencias de resistencia no circulaban en la memoria colectiva sobre la dictadura cívicomilitar. Me propongo reflexionar sobre estas contradicciones, a partir de los esfuerzos de los pueblos del campo $^{6}$ para estar inscritos en la memoria nacional sobre la dictadura cívico-militar (1964-1985), así como en las lucha de estos grupos sociales para ser reconocidos como víctimas de la dictadura y ser reparados por las políticas de la Justicia Transicional en el país. Como más adelante comento, las violaciones que sufrieron los pueblos del campo no están estrictamente vinculadas con las que trata la CVN (tales como haber sufrido detención ilegal o torturas) sino, sobre todo, con ser expulsados de sus tierras y hogares, muertes, entre otros asuntos.

A partir de allí, pretendo reflexionar sobre cómo se dio la "construcción" de las víctimas por parte de la Comisión Nacional de la Verdad, en su relación con las comisiones y comités de verdad que abordaron violaciones contra los pueblos del campo. Para ello, tenemos también en consideración la documentación publicada por las comisiones y comités de verdad, sitios web, blogs, periódicos on-line y entrevistas con investigadores/as y militantes de los derechos humanos.

Comenzaré presentando las acciones de los pueblos del campo relacionadas con las políticas de la justicia transicional, con la organización de documentos, actos políticos, seminarios, creación de comités y comisiones de verdad. Posteriormente, mostraré cómo, a partir de esas movilizaciones, la estructura conceptual normativa de los derechos humanos que orientó la CNV evidencia limitaciones de cara a las

\footnotetext{
4 Para citar algunos ejemplos, las Comisiones de la Verdad de los estados de Minas Gerais y Paraíba concluyeron sus trabajos en diciembre de 2017, entregando sus informes tres años después del fin de los trabajos de la CNV.

5 Cuando la Ley que creó la Comisión Nacional fue instituida, hubo muchas reacciones. El Ministerio de Defensa, por ejemplo, consideró que el proyecto era un insulto para las Fuerzas Armadas. En esa disputa, la Secretaría Especial de Derechos Humanos y el Ministerio de Justicia defendieron la propuesta de manera contundente. Todo ello culminó con la exoneración del jefe del departamento de Ejército, General Maynard Marques Santa Rosa, por ofender a la Comisión.

6 Llamo pueblos del campo a los campesinos, pueblos indígenas, pueblos de la selva y otros pueblos denominados tradicionales. En algunos momentos, haré distinciones a partir de las autodenominaciones que constan en los informes consultados.
} 
complejas realidades y por las distintas formas de violencias que se instalaron en el campo durante la dictadura cívico-militar. No obstante, algunos integrantes de las comisiones de verdad no consideraban las violaciones sufridas por los pueblos del campo como resultado de la represión organizada por el Estado durante la dictadura cívico-militar. Es más: el enfoque pensado para la Comisión Nacional de la Verdad no permitía cuestionar más allá de los Muertos y Desaparecidos, lo que se tornó un obstáculo más para que estos pueblos fueran contemplados por las políticas de la justicia transicional.

\section{Rompiendo con la exclusión: acciones para la construcción de la memoria de los pueblos del campo sobre la dictadura}

En 2011, año en que se aprobó la Ley no 12.528, del 18 de noviembre, que dio origen a la Comisión Nacional de la Verdad, hubo una articulación para la sistematización de los datos sobre la represión en el campo. Esta articulación fue promovida por la Comisión Especial de Muertos y Desaparecidos Políticos (CEMDP), a través de un proyecto Derecho a la Memoria y a la Verdad, dando paso a la publicación de un libro titulado "Retrato de la Represión Política en el Campo. Brasil 1962-1985: campesinos torturados, muertos y desaparecidos" (Carneiro \& Cioccari, 2011). Este proyecto fue realizado por diversos investigadores/as, articulados en el Núcleo de Antropología y Política del Museo Nacional, de la Universidad Federal de Río de Janeiro (UFRJ), en donde funciona el Proyecto Temático llamado Memoria Campesina, coordinado por el Profesor Moacir Palmeira. Este conjunto de investigadores/as llevaban varios años dedicados a abordar temas relativos a la cuestión campesina, investigaciones que posteriormente serían parte de la Comisión Campesina de la Verdad.

Además de los archivos y documentación sistematizados por el grupo Memoria Campesina en el transcurso de varios años, el libro también estaba compuesto por testimonios de campesinos, hijos de militantes y de líderes de organizaciones políticas del campo, fueron recolectados por los/as investigadores/ as en diversos estados del país. Lo que pretendía dicha publicación, viabilizada por el Ministerio de Desarrollo Agrario (MDA) era, como señalan sus organizadoras:

Nuestro interés es que esta publicación, al romper con el silencio y lanzar luces sobre la represión política en el campo entre 1962 y 1985, contribuya a una mejor comprensión de la importancia de la democratización en el mundo rural, siendo ello un imperativo para la democracia y el desarrollo del país como un todo (Carneiro \& Cioccari, 2011:33).

De este proyecto resultó otra colección, de biografías de líderes, titulada: “Colección Campesinos y el Régimen Militar", lanzada en dos volúmenes: "João Sin Tierra: caminos de una lucha" en 2012, y "Japura; un relato de las entrañas del conflicto" en 2013. Sin embargo, según las organizadoras, las publicaciones fueron interrumpidas por falta de financiamiento.

A medio camino de la publicación de estos dos libros, en 2012, la Secretaría de Derechos Humanos de la Presidencia de la República (SDH) presentó un informe a la Comisión Especial sobre Muertos y Desaparecidos Políticos (CEMDP), en la que identificó " 1.196 casos de trabajadores rurales asesinados o desaparecidos por razón ideológica y disputa por tierras en el campo, entre septiembre de 1961 y octubre de 1988, período indicado por la Ley no 9.140/1995” (Viana, 2013:26), o Ley de los Desaparecidos. Los datos resultaron de la investigación hecha por Gilney Amorim Viana y presentados en enero de 2012 en el Foro Social Temático, en Porto Alegre/RS. Un año después, en 2013, este informe fue publicado en forma de libro, “Campesinos Muertos y Desaparecidos: excluidos de la justicia de transición”. En esta publicación se formulan las argumentaciones que sustentan la idea de exclusión en relación a los derechos establecidas en las siguientes leyes: Ley 10.559/2002 (Amnistía Política); 9.140/1995 (Reconocimiento de Responsabilidades 
del Estado) y 12.528/2011 (Memoria y Verdad). Además, se efectúa un relevamiento, mostrando que "Apenas 51 de los 1.196 casos presentaron solicitud a la CEMDP y, finalizando el plazo hábil, los demás 1.144 perdieron la oportunidad de que sus casos fueron examinados. Es decir, excluidos" (Viana 2013:14).

En la época de la publicación del libro, la ministra de Derechos Humanos, María del Rosário Nunes, afirmó que:

La Secretaría de Derechos Humanos al publicar este libro [...], elaborado por el Proyecto Derecho a la Memoria y la Verdad, pretende contribuir con el debate sobre el reconocimiento oficial de los campesinos muertos y desaparecidos en función de las diversas formas de represión política y social en el campo, durante el período 1961-1988 (Viana, 2013:7).

La sistematización de datos sobre la violencia en el campo durante la dictadura pasó, posteriormente, a ser organizada para dialogar con la Comisión Nacional de la Verdad. Sin embargo, antes del inicio de sus trabajos, se enunciaron dos conflictos de gran relevancia dentro de la esfera de disputa de los campesinos: por un lado, la existencia de un silenciamiento sobre la represión política ocurrida en el campo; y por otro, la ausencia de reconocimiento oficial de los muertos y desaparecidos, además de la exclusión de los campesinos de la Justicia Transicional que ya estaba en curso en el país.

Estos libros-informes, que contaban la historia de los campesinos, indicaban un escaso avance en lo referido a la ruptura de la jerarquía social establecida en la sociedad brasileña. Por medio de las biografías, que retoman la memoria de la resistencia de estos sujetos, y su actuación política, se ponen en evidencia los elementos de su identidad. A partir de allí, notamos que el sentido del rescate de la memoria para los pueblos del campo, así como el reconocimientos de los conflictos y resistencias durante la dictadura, son importantes para las luchas por los territorios constantemente amenazados.

Además de los dos proyectos mencionados, las reivindicaciones de los campesinos también se enmarcaron por la vía de movimientos populares, como el de escraches, 7 liderado por Levante Popular de la Juventud (LPJ) durante 2012, y en el cual participaron algunos movimientos campesinos, entre ellos, el Movimiento de los trabajadores Sin Tierra (MST) y el Movimiento de Mujeres Campesinas (MMC). En esta complejidad de luchas en torno de la Memoria, Verdad y Justicia, en el contexto de la conformación de la Comisión Nacional de la Verdad, se realizó el Encuentro Unitario de Trabajadores y Pueblos del Campo, de las Aguas y de las Selvas, llevado a cabo en diciembre de 2012 en la ciudad de Brasilia, ${ }^{8}$ que tenía como tema “Tierra, Territorio y Dignidad”. Este Encuentro Nacional fue construido por varios Encuentros anteriores, pero en el ámbito estadual. Uno de los compromisos asumidos por los movimientos sociales y entidades que estuvieron presentes en el encuentro fue la creación de una comisión de la verdad campesina, que tendría como objetivo

\footnotetext{
7 Los escraches fueron manifestaciones organizadas a nivel nacional, realizadas en los lugares de trabajo o vivienda de agentes de la represión, con el objetivo de denunciar la impunidad y, al mismo tiempo, exigir que sean juzgados por sus crímenes.

8 En este Encuentro se reunieron las siguientes organizaciones y entidades: Asociación de las Casas Familiares Rurales (ARCAFAR); Asociación de las Mujeres de Brasil (AMB); Asociación Brasilera de Reforma Agraria (ABRA); Asociación Brasilera de Estudiantes de Ingeniería Forestal (ABEEF); Articulación Nacional de Agroecología (ANA); Articulación de los Pueblos Indígenas de Brasil (APIB); Consejo Indígena Misionario (CIMI); CARITAS Brasilera; Coordinación Nacional de Quilombolas (CONAQ); Confederación Nacional de Trabajadores en la Agricultura (CONTAG); Comisión Pastoral de Pesca (CPP); Comisión Pastoral de la Tierra (CPT); Central de Trabajadores de Brasil (CTB); Central Única de Trabajadores (CUT); Federación de Estudiantes de Agronomía de Brasil (FEAB); Federación de Trabajadores de Agricultura Familiar (FETRAF); FASE; Greenpeace; INESC; Marcha Mundial de Mujeres (MMM); Movimiento de Afectados por Represas (MAB, por su sigla en portugués); Movimiento Campesino Popular (MCP); Movimiento de Mujeres Campesinas (MMC); Movimiento de Mujeres Trabajadoras Rurales de Noroeste (MMTR-NE); Movimiento de Pequeños Agricultores (MPA); Movimiento de Pescadores y Pescadoras Artesanales (MPP); Movimiento de Trabajadores Rurales Sin Tierra (MST); Movimiento Interestadual de Mujeres Quebradoras de Coco Babaçu (MIQCB); Oxfam Brasil; Pastoral de la Juventud Rural (PJR); Plataforma Dhesca; Red Cefas; Sindicato Nacional de Trabajadores en Investigación y Desarrollo Agropecuario (SINPAF); SINPRO-DF; Tierra de Derechos; Unicafes; Vía Campesina Brasil; Estaban presentes investigadores de universidades federales de Brasilia (UnB), de Rio de Janeiro (UFRJ), de Campina Grande (UFCG), de São Paulo (UNIFESP), de Pernambuco (UFPE), de Minas Gerais (UFMG), de Paraíba (UFPB), de Pará (UFPA), de Goiás (UFG) e de universidades estaduales de Río de Janeiro (UERJ) y de Maranhão (UEMA). Declaración del Encuentro (2012).
} 
[...] luchar por el reconocimiento de la responsabilidad del Estado por la muerte y desaparición forzada de campesinos, así como por los derechos a la reparación a sus familiares, con la creación de una comisión campesina por la amnistía, memoria, verdad y justicia que incida en los trabajos de la Comisión [CNV], proponiendo la inclusión de todos los afectados por la represión (Declaración del Encuentro Unitario, 2012:ítem 11- On line).

De esta manera, destaco dos aspectos importantes de las movilizaciones por Memoria, Verdad y Justicia llevadas a cabo por los pueblos del campo durante 2012. El primero de ellos es el hecho de que importantes movimientos sociales de lucha por la tierra ocuparon las calles, aunque de manera tímida, junto a otros movimientos sociales y entidades de lucha por los derechos humanos, además de la participación en escraches y actos públicos. El segundo aspecto a destacar es que estos movimientos colocaron como pauta específica las violaciones de derechos humanos en el campo, lo cual no sólo involucró a un conjunto de movimientos sociales, sino que permitió la construcción de una comisión de la verdad propia, la Comisión Campesina de la Verdad (CCV), afianzando así la entrada de los campesinos en la disputa por la Memoria, por la Verdad y por la Justicia.

Si bien en el Informe de la Comisión Campesina de la Verdad, publicado en 2015, se afirma que todas las entidades y movimientos que estuvieron en el Encuentro Unitario apoyaron dicha Comisión, en ella participaron activamente las siguientes organizaciones: Confederación Nacional de Trabajadores en la Agricultura (CONTAG); Comisión Pastoral de la Tierra (CPT); Federación de Trabajadores en Agricultura Familiar (FETRAF); Movimiento de las Mujeres Campesinas (MMC); Movimiento de Pequeños Agricultores (MPA); Movimiento de Trabajadores Rurales Sin Tierra (MST); Relatoría del Derecho Humana a la Tierra, Territorio y Alimentación de la Plataforma DHESCA; Plataforma Brasilera de Derechos Humanos, Económicos, Sociales, Culturales y Ambientales; y la Red Nacional de Abogados y Abogadas Populares Tierra de Derechos (RENAP).

Entre las acciones que los pueblos del campo realizaron por el derecho a la Memoria, a la Verdad y a la Justicia, destaco la reunión mantenida por la Comisión Nacional de la Verdad con diversos comités y entidades de lucha por los derechos humanos ligados a la disputa por Memoria, Verdad y Justicia, realizada en Brasilia en 2012, apenas iniciado el funcionamiento de la Comisión. En la oportunidad, los comités elaboraron un documento denominado Carta de los Comités a la Comisión Nacional de la Verdad ${ }^{9}$, con el objetivo de posicionar sus demandas y orientar los trabajos de la CNV. Los comités, en su mayoría, fueron formados en 2012, en el contexto de la implementación de la CNV. Cabe mencionar que ninguno de ellos se definía específicamente como campesino o indígena. Sin embargo, la pauta de los pueblos del campo fue incorporada al documento. La Carta de los Comités fue estructurada en 14 puntos $^{10}$. Ya en el primero se hacía referencia a las violaciones de derechos humanos en el campo:

\footnotetext{
9 Este documento fue producido el 30 de julio de 2012, en Brasilia, y firmado por las siguientes entidades: Asociación de los Amigos del Memorial de la Amnistía Política de Brasil; ATAMIG - Asociación de Trabajadores Amnistiados, Autónomos, Liberales, Pensionados de Minas Gerais; Centro de Derechos Humanos y Memoria Popular de Foz de Iguaçu; Colectivo Catarinense Memoria, Verdad y Justicia; Colectivo RJ Memoria, Verdad y Justicia; Comisión de la Verdad y del Memoria de la Amnistía OAB/MG; Comité Carlos de Ré de la Verdad y de la Justicia; Comité Estadual por la Memoria, Verdad y Justicia de Mato Grosso Sur; Comité Estadual por la Memoria, Verdad y Justicia de Rio Grande del Norte; Comité Goiano de la Verdad, Memoria y Justicia; Comité Maranhense de la Verdad; Comité Memoria, Verdad y Justicia de Paraíba/PI; Comité Memoria, Verdad y Justicia de Pernambuco; Comité Paraense en Defensa de la Comisión de la Verdad; Comité Paulista por la Memoria, Verdad y Justicia; Comité por la Verdad, Memoria y Justicia del Distrito Federal; Comité por la Verdad, Memoria y Justica de Campinas; Comité por la Verdad, Memoria y Justicia de Pelotas y Región; Comité por la Verdad, Memoria y Justicia de Piauí; Comité por el Derecho a la Memoria, a la Verdad y a la Justicia de Ceará; Comité de Santamariense de Derecho a la Memoria y a la Verdad - Santa María/RS; Foro Derecho a la Memoria y a la Verdad del Estado de Espíritu Santo; Grupo Tortura Nunca Más- PE - Núcleo de Memoria; Grupo Tortura Nunca Más - SP; Núcleo de Preservación de la Memoria Política - São Paulo.

10 Los demás puntos hacen referencia a la investigación de crímenes contra los muertos y desaparecidos políticos; la creación de audiencias públicas; la necesidad que la comisión estableciera un diálogo constante con la sociedad civil, que permitiera transparencia y difusión de sus trabajos, además de dejar en claro las responsabilidades de quienes organizaban la represión.
} 
Esclarecer también los casos de graves atentados a los derechos humanos llevados a cabo durante el período pre-golpe militar de 1964 (1961-1964), como por ejemplo, el asesinato y desaparición en 1962 de Pedro Fazendeiro y Nego Fubá, de las Ligas Campesinas (PB), considerados los dos primeros desaparecidos políticos, así como durante el gobierno de transición civil (1985-1988), tal y como lo determina la Ley 9.140/1995 (Carta de los Comités, 2012: Ítem 1).

En las recomendaciones siguientes de la Carta, el tema sobre violaciones de derechos en el campo se amplía, haciendo referencia también a los pueblos indígenas y a las comunidades tradicionales, exigiendo la responsabilidad del Estado, pero apuntando hacia la dimensión privada de la represión contra estos pueblos:

Esclarecer las graves violaciones de derechos humanos cometidos contra campesinos, trabajadores rurales, pueblos indígenas, pequeños mineros, comunidades tradicionales, por parte de agentes del Estado y por agentes privados a su servicio, o apoyados por agentes del propio Estado, además de apreciar otras sugerencias de líneas de investigación específicas (Carta de los Comités, 2012: Ítem 5).

Con relación a los campesinos, en este documento se reconoce la necesidad de que la CNV se articule con los movimientos sociales y otras entidades ligadas a la lucha campesina. De esta manera, las entidades organizadas proponían un camino posible para investigar las violaciones de derechos humanos ejecutadas en el campo:

Promover asociaciones con entidades representativas del campesinado, ya sea sindicales, como CONTAG, FETRAF, CUT, CTB, entre otras centrales sindicales; con movimientos populares como el MST, el MLST, entre otros; desarrollar una línea de investigación y esclarecimiento sobre las graves violaciones de derechos humanos cometidas contra campesinos y trabajadores rurales, en sentido amplio, incluyendo los crímenes cometidos por policías privados paraestatales y agentes privados en complicidad con poderes del Estado; promover asociaciones con entidades representativas del campesinado [...], con movimientos populares [...]. Consultar entidades y especialistas sobre Luchas Campesinas, Memoria Campesinas e Investigación sobre Represión a los movimientos campesinos, como la Comisión Pastoral de la Tierra (CPT), la red académica de investigación sobre la Memoria Campesina, entre otros; recopilar testimonios de sobrevivientes de las masacres, asesinatos y actos represivos a campesinos; consultar los documentos de los casos que fueron objeto de Investigaciones Policiales y Procesos Judiciales; investigar y analizar la relación entre el aparato represor de la época de la dictadura y la actividad policial y de milicias de latifundistas actualmente existentes; producir un informe específico sobre los graves atentados a los derechos humanos contra los campesinos (Carta de los Comités, 2012. Ítem 5).

La ceremonia que creó la CNV fue realizada en el Palacio del Planalto, donde la presidenta Dilma Rouseff puso en funciones a los siete comisionados nombrados por ella, tal y como había sido previsto en la Ley que creara la Comisión, Ley no. 12.528/2011 ${ }^{11}$.

Entre las preocupaciones de los grupos organizados en la sociedad civil estaba la presencia de los militares en la Comisión de la Verdad, como también la ausencia, entre los comisionados, de entidades que representaran a los Familiares, como había ocurrido en el caso de la Comisión de la Verdad en Argentina (Pinto, 2010). No obstante, como se ha mencionado, los integrantes fueron escogidos por la Presidenta de la República, a partir del prestigio de cada uno de ellos en sus respectivas carreras. Esto no evitó divergencias

11 Los miembros indicados fueron: José Carlos Dias (abogado, ex-ministro de Justicia), João Paulo Cavalcanti Filho (abogado), Maria Rita Kehl (psicóloga), Paulo Sérgio Pinheiro (politólogo), Rosa Maria Cardoso da Cunha (abogada), Cláudio Fonteles (abogado), quien dejó la comisión en junio de 2013 y fue reemplazado por Pedro Dallari (abogado), y Gilson Dipp (abogado), quien también se retiró de la comisión en diciembre de 2012 , pero no fue sustituido. Como se evidencia, la mayoría de ellos eran juristas, lo que implicó poca diversidad, contrariando lo previsto en la Ley (Pereira, 2016). 
significativas entre ellos, como se puso en evidencia en los trabajos de la Comisión Nacional de la Verdad; en parte, por no tener afinidad ideológica, de experiencia u orientación entre sí. Al contrario, prevaleció, en muchas ocasiones, la opinión personal, en completa falta de acuerdo con las luchas en torno a cómo conducir el proceso.

Al consultar la prensa nacional de la época de creación de la CNV, creada en el año 2012, como el periódico "O Globo", de gran circulación, es posible observar que se presentaron dificultades con relación a temas cruciales, tales como la discreción en el trabajo de la CNV, la revisión de la Ley de Amnistía, la investigación de los supuestos "crímenes de izquierda", entre otros desaciertos internos, que influyeron y perjudicaron el trabajo de la Comisión Nacional de la Verdad. Además, su relación con la sociedad civil estuvo marcada por tensiones, lo que terminó en una constante y amplia crítica por parte de los militantes de Derechos Humanos.

La Comisión Nacional de la Verdad se organizó estructuralmente en 13 grupos de trabajo temáticos. ${ }^{12}$ No todos nacieron al mismo tiempo: la CNV era, en sí misma, un espacio de disputa. Familiares, comités de verdad, comisiones estaduales, sindicatos y militantes se movilizaron para impedir que sus pautas fueran excluidas de la CNV.

En lo referente a los pueblos del campo, las recomendaciones propuestas en la Carta de los Comités fueron incorporadas por la CNV al crear, mediante la resolución no. 5/2012, el Grupo de Trabajo (GT) presidido por la comisionada María Rita Kehl'13 sobre "Violaciones de derechos humanos, practicadas por motivación política, relacionadas a la lucha por la tierra o contra los pueblos indígenas", con competencia para:

I - Esclarecer hechos, circunstancias y autorías de casos graves de violaciones de derechos humanos, como torturas, muertes, desapariciones forzadas, ocultamiento de cadáveres, relacionados a los grupos de los que trata el capítulo; II - identificar y hacer públicos estructuras, lugares, instituciones y circunstancias de violaciones de derechos humanos cometidas contra los grupos de los que trata el capítulo; III - examinar acervos referentes a la temática; y IV - brindar apoyo al informe mencionado en el art. 11 de la Ley no. 12.528 (CNV 2012: Resolución no 5 Online).

Una de las particularidades sobre los campesinos es el desconocimiento de este grupo social por parte de las políticas de justicia transicional implementadas en Brasil (Viana, 2013; Carneiro \& Cioccari, 2011). Como se dijo, entre dichas políticas está el desconocimiento de derechos establecidos en la Ley no. 9.140/1995, que creó la Comisión Especial de Muertos y Desaparecidos Políticos; y la Ley no. 10.559/2002, que creó la Comisión de Amnistía (CA). Los campesinos, sus familias y las organizaciones de las que ellos eran parte no percibieron reparación; fueron pocas las personas de este grupo social contempladas en esas políticas, así como insuficiente el énfasis en los campesinos puesto por parte de la Comisión Nacional.

Estas contradicciones contribuyeron de manera decisiva en la creación de la Comisión Campesina de la Verdad (CCV), instituida en mayo de 2013.14 Si bien esta comisión tuvo el apoyo oficial de la Comisión Nacional de la Verdad, los recursos disponibles no fueron suficientes para profundizar el proceso de investigación. La Comisión Campesina de la Verdad contó también con el apoyo de otras entidades,

\footnotetext{
12 Los Grupos de Trabajo fueron: 1) Dictadura y género; 2) Araguaia; 3) Contextualización, fundamento y razones del golpe cívico-militar de 1964; 4) Dictadura y sistema de Justicia; 5) Dictadura y represión a los trabajadores y movimiento sindical; 6) Estructura de represión; 7) Muertos y desaparecidos políticos; 8) Graves violaciones de derechos humanos en el campo o contra indígenas; 9) Operación Cóndor; 10) Papel de las iglesias durante la dictadura; 11) Persecuciones a militares; 12) Violaciones de derechos humanos de brasileños en el exterior, y de extranjeros en Brasil; y 13) el Estado dictatorial-militar.

13 En el artículo 2o de la Resolución se preveía, para la composición del GT, además de Maria Rita Kehl, miembros como: Heloísa Maria Murgel Starling; Pedro Helena Pontual Machado; Wilkie Buzatti Antunes y Inimá Ferreira Simões.

14 Su coordinación general estuvo a cargo de Cléia Anice da Mota Porto, de la CONTAG/ABRA; del Profesor Sérgio Sauer, de la Universidad de Brasilia; y de Gilney Amorim Viana, de la Secretaría de Derechos Humanos de Paraná ( CCV, 2014:4).
} 
como la Confederación Nacional de los Trabajadores en la Agricultura (CONTAG), cuya sede nacional, ubicada en Brasilia, sirvió de espacio para la realización de las reuniones de esta Comisión. La CCV estuvo conformada por 58 personas, entre investigadores, gestores públicos y representantes de movimientos sociales, en su mayoría, con antecedentes de apoyo a los movimientos sociales y sindicales (Welch, 2014).

De acuerdo con Saraiva y Sauer (2015), en la búsqueda de accionar el "derechos a la memoria” y darle "visibilidad (oficial)", se estableció un diálogo constante con la Comisión Nacional de la Verdad por medio de la comisionada Maria Rita Kehl. La CCV culminó sus trabajos en 2014, presentando su informe final en diciembre del mismo año.

Los campesinos también fueron tema en otras comisiones de verdad en el país, como la Comisión de la Verdad de Río (CV-Rio), en cuyo informe existe un capítulo denominado "Conflicto y represión en el campo" (Informe CVE-Rio, 2014); la Comisión de la Verdad Rubens Paiva (CVRP) del estado de São Paulo, en donde se organizó también un Grupo de Trabajo denominado "Represión en el campo en el estado de São Paulo, 1946-1988" (Informe CVRP-SP. Tomo IV, 2015), que tenía como propósito investigar las violaciones a los pueblos del campo durante la dictadura militar, proporcionando conocimiento relevante sobre lo ocurrido a campesinos y, en muchas ocasiones, estableciendo una relación conflictiva con la CNV.

Para citar un ejemplo, el concepto de graves violaciones de derechos humanos fue especialmente objetado por estas comisiones, a partir de la realidad de los campesinos. Para la Comisión Nacional de la Verdad, las graves violaciones se restringían a la tortura y la desaparición forzada. Cuestionando esta conceptualización, la Comisión Rubens Paiva desarrolló una metodología de análisis teniendo como fundamento la Declaración Universal de los Derechos Humanos, que dio como resultado " 465 eventos de violaciones, involucrando más de 300 mil campesinos en el estado de São Paulo" CRPV (Tomo IV 2015:2). Con ello, corroboró las reivindicaciones presentadas por la Comisión Campesina de la Verdad, que privilegió otras formas de categorización, ofreciendo una dimensión mucho mayor de la violencia en el campo: aquella que se verificaba en el cotidiano, especialmente en contextos de luchas campesinas por derechos laborales o en disputas por los territorios, como por ejemplo, la destrucción de sus hogares, persecuciones y asesinatos.

Desde el punto de vista de las reivindicaciones, la Comisión Campesina de la Verdad se reconoció como heredera de la "lucha contra el olvido y la invisibilidad, en la búsqueda de la verdad, la reparación y la justicia" (Informe CCV, 2014:20), reconocimiento que fue construido por la Comisión Especial de Familiares de Muertos y Desaparecidos Políticos de 1995; el Grupo Tortura Nunca Más, de 1985; y los Comités por Memoria, Verdad y Justicia creados a partir de 2011. A partir de estas políticas, los campesinos y pueblos indígenas, a través de comisiones de verdad, consiguieron reivindicar, ante agencias internacionales como la Organización de Naciones Unidas (ONU), la Organizaciones de Estados Americanos (OEA)y la Organización Internacional del Trabajo (OIT), el cumplimiento de los compromisos internacionales suscriptos por el Estado, especialmente, aquellos firmados en la Convención Americana de Derechos Humanos (CADH). ${ }^{15}$

En la misma perspectiva de otros grupos sociales, los pueblos del campo defienden la tesis de que "la interpretación y la aplicación dada a la Ley de Amnistía (Ley no. 6.683/79) ha impedido la investigación y la sanción de graves violaciones de derechos humanos ocurridas durante la vigencia de la dictadura cívicomilitar" (CCV, 2014: 386), incumpliendo, de esta forma, los acuerdos internacionales firmados por Brasil.

Como pudimos observar, la Comisión Campesina de la Verdad nació y trabajó dentro de la perspectiva de que existe un "proceso político y social de invisibilización de la lucha campesina, de resistencia a la dictadura y de procesos de reparación en curso en el Estado brasileño" (CCV, 2014:14). De esta manera,

15 Aunque esta información fue extraída del informe de la Comisión Campesina de la Verdad, se hace referencia sobre este aspecto en diversos informes sobre la cuestión indígena. 
el informe sustenta la idea de injusticia en relación a las violaciones cometidas contra los campesinos, a la vez que hace explícita la ausencia de reconocimiento de dichas violaciones por parte de los mecanismos de reparación consolidados en el país, reafirmando a los campesinos como un segmento social olvidado por el Estado en lo relativo a las medidas de reparación ya instituidas.

En este sentido, las preocupaciones teórico-conceptuales y políticas de la Comisión Campesina se articularon para condicionar el trabajo de la CNV. Por ejemplo, se movilizó el concepto de memoria, con el objetivo tanto de narrar e inscribir dentro de la historia del país las experiencias campesinas, como de quebrar la invisibilidad e incorporar a los campesinos en el debate público sobre la dictadura cívico-militar y hacer justicia:

Presentificar, entendido como acción de traer el pasado al presente, teniendo como soporte la memoria no solamente como registro, o como un fin nostálgico, sino como acción y reivindicación de justicia. En este sentido, futuro y justicia caminan juntas (CCV, 2014:17).

De manera general, es posible percibir que el repertorio movilizado para justificar la Comisión Campesina de la Verdad no difiere de otros que surgieron en el mismo año. Se trata de un repertorio ya consolidado en las luchas por Memoria, Verdad y Justicia, desde la época de la dictadura cívico-militar. Como se ha dicho, la Comisión Campesina de la Verdad adviertió que la memoria accionada tiene como finalidad la reconstrucción de la verdad, para alcanzar justicia. Además, reivindicó la incidencia de las políticas de justicia transicional sobre las instituciones y sus políticas, para que "las violaciones no se repitan". Estas demandas tenían como objetivo "fortalecer la lucha por el derechos a la memoria, a la verdad, a la amnistía y a la justicia con relación a las violaciones de derechos humanos cometidas en el campo" (CCV, 2014:386).

Con ello, los pueblos del campo también reivindicaron ser reconocidos por las políticas de justicia transicional, al tiempo que denunciaban las violaciones que involucran derechos fundamentales, "como el derecho al trabajo, a la educación, a la vivienda, a la tierra y a la vida, el derecho a la libre asociación y organización, y derechos laborales" (CCV, 2014:385) que están regulados, tanto por el Derecho Nacional, como por el Derecho Internacional. Al hacer esto, interpelaron las normativas sobre violaciones de derechos humanos constituidas, produciendo otras formas de análisis para aprehender realidades.

\section{La Comisión Nacional de la Verdad y el reconocimiento de las víctimas del campo}

Pocos días antes de la entrega del informe final de la Comisión Nacional de la Verdad, el 25 de noviembre de 2014, la Comisión Campesina de la Verdad publicó un documento, que circuló por distintos espacios, expresando su desacuerdo sobre el número de "muertos y desaparecidos" que la Comisión Nacional reconocería en su Informe Final: ${ }^{16}$

[...] señalamos nuestra preocupación con la información de que la CNV reconocerá oficialmente apenas un número aproximado de 430 muertos/as y desaparecidos/as, que hacen referencia en casi su totalidad a nombres y casos ya reconocidos. Confirmándose esta información, se consagra la exclusión de las políticas de reconocimiento oficial a la mayoría de campesinos y campesinas muertos/as y desaparecidos/as, haciéndoles difícil el acceso a la justicia de transición. Se destaca que la Comisión Campesina de la Verdad entregó informe detallado de graves violaciones de derechos humanos de los campesinos a la CNV, incluyendo una lista de 1.196 campesinos y campesinas muertos/as y desaparecidos/as. Reivindicamos el reconocimiento oficial de todos los campesinos muertos y desaparecidos en el informe de la CNV (CCV: 25/11/2014).

16 Recibí este documento por e-mail a través de la Secretaría de Post-Grado en Ciencias Sociales IFCH/Unicamp. 
En ese documento, la CCV reconocía el importante trabajo que la Comisión Nacional de la Verdad estaba realizando, y complejizaba el campo de diálogo sobre esta cuestión. Un día después de la entrega del informe de la Comisión Nacional de la Verdad, el tema de los pueblos del campo fue tema en un debate realizado en el Senado Federal. Gilney Amorim Viana, quien participara de la Comisión Campesina de la Verdad, afirmó que el informe era 'débil', porque no tenía en cuenta a los “1.200 campesinos" y a los "8.00o indígenas" que también fueron víctimas de la dictadura. (Éboli apud Jornal O Globo 11-12-2014) .

Diversas investigaciones han señalado los importantes avances del trabajo de la CNV, de su informe, y también, de sus límites. La CNV llevó al debate público una serie de temas silenciados o poco conocidos sobre los años de la dictadura. Estos avances tuvieron como base la posibilidad de que las víctimas hablaran, así como la posibilidad de establecer asociaciones con instituciones durante los procesos de investigaciones (Canabarro, 2014); el informe producido por la CNV presenta aspectos centrales del sistema represivo, trazando el camino de cómo este sistema operaba en Brasil y en el exterior; y se registra la asociación de las clases burguesas brasileñas en lo relativo al golpe y a su financiamiento para la represión política (CNV, 2014b:88 y 199).

El conocimiento sistematizado por la Comisión Nacional de la Verdad, con base en múltiples investigaciones académicas, desmitificó la idea dicotómica un Estado ocupado por militares golpistas y una sociedad civil pasiva en su conjunto, en relación a lo que estaba sucediendo. El informe nos revela las múltiples formas de resistencia a la dictadura por parte de diversos grupos que se organizaron contra los gobiernos militares; a la vez que subyace, en el mismo informe, la comprensión de que diversos sectores de la sociedad se articularon para dar sustento al poder gubernamental de los militares. Además, desde el punto de vista jurídico, el informe crea la posibilidad de legislar sobre crímenes, "pues creó la posibilidad ética y política de justicia al establecer una distancia entre la víctima y el agresor [...]” (Pereira, 2015:894). Estos trabajos apuntan en un mismo sentido: la entrega del informe no representó un punto final en la investigación y en el ámbito de la justicia transicional en el país (Schinke, 2016).

Sin embargo, al mismo tiempo en que echó luz sobre importantes cuestiones, quedaron otras a la espera de una atención diferenciada, a saber: los crímenes cometidos contra los pueblos del campo. Deducimos de esto que las categorías Memoria, Verdad y Justicia que forman parte de la estructura conceptual normativa de los organismos de derechos humanos, son categorías cuyas dinámicas están sometidas a las relaciones de poder, de posición social, de clase y de cultura que los sujetos ocupan en la sociedad, lo que impone más desafíos para algunos grupos que para otros a la hora de su reconocimiento.

En lo referente a los pueblos del campo, los plazos limitados para realizar solicitudes a la Comisión Especial de Muertos y Desaparecidos Políticos, organizada por la Ley no. 9.140/95, significó una barrera al examen de posibles reclamaciones realizadas por familiares de campesinos muertos y desaparecidos. La referida ley preveía la posibilidad de reconocimiento de la responsabilidad estatal por muertes y desaparición por motivación política, ejecutadas durante el período comprendido entre el o2 de septiembre de 1961 y el 15 de agosto de 1979. Aproximadamente una década más tarde, la Ley 10.536/02 amplió este período. No obstante, estableció un plazo de 120 días para registrar las solicitudes, contados a partir de la fecha de publicación de la Ley (Viana, 2013:37). Los pueblos que viven en el campo desconocían estas informaciones, o las recibieron fuera de plazo, por lo que no consiguieron presentar solicitudes de reconocimiento de tal derecho.

En los casos en que sí consiguieron presentar pedidos de reparación, la Ley no contemplaba las violaciones de derechos que denunciaban y a las que fueron sometidos. Además, existe poca documentación sobre las formas en que la dictadura afectó a este grupo. Entre los agentes que perpetraran violaciones a estas poblaciones se encontraban pistoleros, terratenientes, policías locales e incluso, las Fuerzas Armadas, como en el caso del bombardeo con napalm a la Guerrilla Vanguardia Popular Revolucionaria en el "Vale do 
Ribeira" de São Pablo, que afectó a muchos campesinos de esa zona. La concepción restringida de la idea de violaciones, víctimas y victimarios se expresó, por ejemplo, en la contabilización del número de víctimas, poniendo en evidencia el proceso de "invisibilización" de los sujetos afectados. El informe de la Comisión Campesina de la Verdad así lo afirma:

Los/as campesinos/as, perseguidos/as políticos/as y afectados/as por la represión durante el período de 1946 y 1988, pocos/as fueron objeto de proceso judicial, de apertura de investigación policial-militar, o de cualquier otro tipo de registro oficial ante el Sistema de Justicia y Seguridad Pública, ni ante la Justicia Militar (CCV, 2014:386).

Los pueblos del campo tienen dificultades para demostrar que las violaciones sufridas sean calificadas como violaciones de derechos humanos. Me refiero a que lo que han vivido no está estrictamente vinculado con haber sufrido detención ilegal o torturas, sino sobre todo con sus modos de reproducción vital, con ser expulsados de sus tierras y hogares, con envenamientos, entre otros asuntos que se detallan más adelante. Teniendo en cuenta que esta ausencia de información sobre las víctimas de la dictadura en el campo impedía su reparación, la Comisión Campesina de la Verdad tuvo como objetivo la sistematización de informaciones, con la finalidad de que se ampliaran los criterios de reconocimiento de la violencia, enfocándose, por ejemplo, en la conceptualización de graves violaciones de derechos humanos.

Fue en este sentido que la Comisión Campesina de la Verdad trabajó para constituir otras definiciones de víctimas y de agentes perpetradores, a ser reconocidas por las normativas del derecho internacional y para que las víctimas tuvieran sus reivindicaciones atendidas específicamente. Así, la conceptualización política del Estado como sujeto de violación de derechos humanos dirigió el debate de la Comisión Campesina de la Verdad, la cual, a su vez, identificó que entre las acciones represivas estaban aquellas realizadas directamente por el Estado, representado en las Fuerzas Armadas y las Policías locales, así como en otros actores, cuyos crímenes eran de participación indirecta de agentes del Estado, ya fuera "por connivencia, omisión o complicidad en la ejecución de procesos administrativos, investigativos y criminales" (CCV, 2014:385).

La realidad del campo llevó a una actuación específica del Estado, determinando agentes perpetradores de violencia y construyendo perfiles de víctimas vinculados a ese contexto, que deben ser entendidos en ese sentido, como puede observarse en el discurso de Nicinha Porto, entrevistada por la periodista Michelle Canes para una nota online publicada pela Agencia Brasil:

[...] el material [informe de la CCV] señala, además de las violaciones y víctimas, cuestiones que necesitan ser observadas cuando el escenario es el medio rural, por ejemplo, la figura de quién agencia contra los campesinos. [... ' No necesariamente estaba presente en el acto físico de la represión el delegado de policía o un policía uniformado. Pero estaban presentes pistoleros, sicarios. Es este concepto de agente del Estado que necesita ser analizado (Porto in Agencia Brasil on line, 11/12/2014)

En lo referido a las demandas de reparación, éstas también son específicas, tal y como se constata en las recomendaciones propuestas en el informe de la Comisión Campesina de la Verdad. Además de la reparación individual económica, se recomienda la implementación de diversas políticas públicas, como por ejemplo, la Reforma Agraria, como forma de reparación colectiva y de avance en el proceso de democratización del campo brasileño. 
Según Nicinha Porto, "las violaciones relacionadas con el campo tienen relación directa con el proceso de apropiación de la tierra, por lo que la reforma agraria es una causa estructural de la violencia actualmente, y ella fue la gran bandera del pasado" (Agencia Brasil On line, 11/12/2014. Como podemos observar en el trabajo adelantado por la Comisión Campesina de la Verdad, fue la movilización por el derecho fundamental a la tierra el resorte que estimuló las violaciones de derechos humanos en el campo.

En la misma línea, Sônia Guajajara, de la Articulación de los Pueblos Indígenas de Brasil (APIB), afirma que:

[...] fue exactamente durante el período de la dictadura que se presentó el mayor robo de tierras indígenas, lo que intensificó el conflicto por la demarcación de tierras. Actualmente, para nosotros, pueblos indígenas, la mayor reparación que queremos por parte del Estado es la regularización de los territorios indígenas para los pueblos del país (Guajarara, in Agencia Brasil On line, 11/12/2014).

De la misma manera, durante la dictadura militar el ataque sistemático a los pueblos indígenas estuvo vinculado a sus luchas por la garantía de su sobrevivencia y sus modos de vida en sus territorios. Tanto la reforma agraria como la demarcación de las tierras indígenas son recomendaciones que iluminan sobre las especificidades de estos grupos sociales y cuestionan los tipos de normatización con fines reparatorios que sustentan la justicia transicional brasileña.

La cuestión de los pueblos del campo fue incorporada en el informe de la Comisión Nacional de la Verdad con algunos límites de reconocimiento, lo que desentonó con los resultados presentados por las comisiones de verdad que se dedicaron al tema. El informe de la CNV está dividido en 3 volúmenes. En lo relativo a los pueblos indígenas, los tipos de violaciones presentadas por las comisiones de la verdad están principalmente en el Volumen II. Los temas específicos de los campesinos, además del Volumen II, están presentes en la parte IV del Volumen I, en el capítulo 13 titulado "Casos emblemáticos", y más específicamente, en la subdivisión 13-B llamada "La Represión contra trabajadores, sindicalistas y campesinos". En este capítulo, fueron dos casos los abordados sobre la problemática campesina: "El Levantamiento de Tromba y Formoso", citando dos víctimas, José Porfirio y su hijo Durvalino Porfirio de Souza. El segundo de ellos fue "Operación Mesopotamia: la represión en área rural en la frontera entre Mato Grosso y Goiás”, citando la represión contra Epaminondas Gomes de Oliveira.

Sobre las víctimas citadas en los dos casos escogidos, fueron personas con amplia experiencia militante, que formaron parte de algunas organizaciones y sindicatos. José Porfirio fue el primer diputado campesino en Brasil, militante del Partido Comunista Brasileño. En ambos casos, fueron ejecutadas violaciones: "tortura", "muerte", "desaparición forzada", "ocultamiento de cadáveres", de acuerdo a lo establecido en la Resolución no 5 del 5 de noviembre de 2012, que creó el Grupo de Trabajo sobre represión en el campo en el ámbito de la Comisión Nacional de la Verdad.

La cuestión campesina aparecerá nuevamente en el Volumen I del Informe, junto con la cuestión indígena, en el capítulo sobre la Guerrilla de Araguaia. ${ }^{17}$ Como en los dos casos citados, en este último, la represión que los campesinos sufrieron está vinculada a la presencia del Ejército, toda vez que fueron encuadrados como auxiliares de la guerrilla. Este espacio del texto hace mención a las operaciones militares "Sucuri” y "Marajoara", ambas ocurridas en 1973 y que tuvieron como objetivo la "neutralización de la red de apoyo" de los guerrilleros de Araguaia, quienes, en este caso, no eran otros que indígenas y campesinos (CNV, 2014:701).

17 La guerrilla de Araguaia fue un movimiento armado contra la dictadura militar organizado por el Partido Comunista de Brasil (PCB), que actuó durante tres años en el estado de Pará, y fue desarticulado por las Fuerzas Armadas Brasileñas. 
A partir de los trabajos de la Comisión Campesina de la Verdad, la Comisión Nacional de la Verdad consideró como violaciones las siguientes acciones: "ejecuciones", "detenciones ilegales en masa", "desaparición" y “ocultamiento de cadáveres". Y llevado al escenario específico de la represión a la Guerrilla de Araguaia, se suman otros tipos de violaciones contra indígenas y campesinos, como "tortura", "violación o estupro", "Privación de libertad", "trabajo forzado como guía para las Fuerzas Armadas", "Privación de los medios de sobrevivencia (quema de casas, alimentos y cultivos)" y "golpizas".

Frente a las acciones listadas, la Comisión Nacional de la Verdad, a partir de la Ley 9.140/95 indicó a 6 campesinos como posibles víctimas, siendo 4 de ellos considerados desaparecidos políticos cuyos perfiles están presentes junto al conjunto de víctimas oficialmente reconocidas en el Volumen III del Informe (CNV, 2014:176). A partir de allí, se observa que para la Comisión Nacional de la Verdad, las víctimas son apenas quienes sufrieron represión política directa por parte de las Fuerzas Armadas. Solamente los sujetos que fueron definidos por esta institución como "subversivos" o "terroristas" fueron considerados víctimas por la Comisión Nacional de la Verdad. Se verifica que las diferentes formas de represión y otras dimensiones de violencia ocurridas en el campo no fueron consideradas. Los muertos por esas otras formas de violencia no fueron nombrados como víctimas y, por tanto, fueron excluidos del reconocimiento y consecuentemente de las políticas de reparación.

\section{Los pueblos indígenas y los límites de la justicia transicional}

El proceso de invisibilización sufrido por los pueblos indígenas es todavía más intenso que el de los campesinos. Hasta la actuación de la CNV no se había dado a conocer las violaciones de la dictadura contra esas poblaciones, ni vías o espacios para demandar algún tipo de reconocimiento y/o reparación. Sin embargo, las acciones de la CNV no fueron suficientes para dilucidar todos los crímenes cometidos contra los pueblos indígenas. Así, durante la actuación de la CNV, fueron realizadas trece audiencias públicas sobre la cuestión indígena entre mayo de 2012 y noviembre de 2014, de las cuales cuatro de estas audiencias fueron articuladas con otras comisiones. Además, la Comisión de Derechos Humanos y Minorías de la Cámara Federal (CDHM) realizó dos audiencias; la Comisión de Derechos Humanos y Participación Legislativa (CDH) realizó una audiencia; y la Comisión Estadual de la Verdad Teresa Urban, de Paraná18, realizó otras dos audiencias ${ }^{19}$ y contribuyó a la CNV con un informe sobre los pueblos indígenas de las Cuencas Hidrográficas del Tibaji, Laranjinha y Cinzas, en el estado de Paraná. Por otro lado, la Comisión de la Verdad Aikewara se trata de una comisión especial por su significado desde el punto de vista de la amplia participación del pueblo Aikewara y de las controversias evidenciadas en el informe. En el estado de São Paulo, la Comisión Rubens Paiva realizó tres audiencias públicas sobre violaciones de derechos humanos contra los pueblos indígenas.

Todas esas comisiones organizaron o fueron organizadas por grupos formados por historiadores/as y antropólogos/as, que asumieron la posición de mediadores/as entre los pueblos indígenas afectados y el Estado. Muchos de ellos ya tenían alguna experiencia de estudio y/o relación con dichos pueblos, por lo que produjeron y sistematizaron documentos, se involucraron a partir de la realización de seminarios y encuentros temáticos. Además, investigaron en archivos y entrevistas con los pueblos indígenas, con el objetivo de que la información referente a las violaciones y las múltiples etnias que fueron violentadas llegara a la Comisión de la Verdad.

\footnotetext{
18 Organizado en el GT 6: "Violaciones en el Campo y Pueblos Indígenas". Olympio de Sá Sotto Maior (coordinador), Ângelo Priori (desde marzo de 2014), Márcio Kokoj: miembro de la Articulación de los Pueblos Indígenas de la Región Sur (ARPINSUL).

19 Datos obtenidos a partir del "Centro de Referencia Indígena do Armazén da Memória”.
} 
En mayo de 2012, mes en el que también se creó la Comisión Nacional de la Verdad, se constituyó el Comité Estadual de Derecho a la Verdad, a la Memoria y a la Justicia del Estado de Amazonas (CEMVJ-AM), dentro de la Universidad del Amazonas. Este comité produjo un informe sobre las violaciones de derechos humanos perpetradas contra el pueblo Waimiri-Atroari, en el contexto de la apertura de la carretera BR-174 que conecta Manaus (AM) con Boa Vista (Roraima-RR), entre los años de 1972 y 1977.

El informe fue producido para ayudar a la CNV y al Ministerio Público Federal en la investigación de crímenes de la dictadura militar ejecutados en el estado del Amazona [...] es un manifiesto para que se haga justicia con relación al pueblo Waimiri-Atroari (CEMVJ-AM, 2014:8).

En este informe, el pueblo Kiña o Waimiri-Atroari, que hasta 1967 vivía en la región entre Manaus (AM) y Caracaraí (RR), denunciaba las violaciones sufridas. Así, este informe se hizo público en 2012 gracias a la acción del Comité de la Verdad del Amazonas y por la iniciativa de la diputada federal Luiza Erundina (PSBSP), quien realizó ese año, juntó a la Comisión de Derechos Humanos de la Cámara Federal, una audiencia pública para tratar la muerte de 2.00o Kiña. "Entre 1972 y 1975 la población Kiña se redujo de 3.000 a 1.000 personas, sin que la FUNAI (Fundación Nacional del Indio) ni los militares expusieran las causas de dicha reducción. Esos 2.00o Kiña desaparecieron sin que se hiciera una sola acta de defunción" (Schwade in Carta Capital online, 22-2-2011). Esta práctica de no registrar muertes era común con respecto a los pueblos indígenas. Por ejemplo, exterminios por contagios a partir del contacto con equipos de sertanistas, o por el contacto con residuos hospitalarios arrojados intencionalmente en las aldeas, no fueron notificados por la FUNAI (Valente, 2017).

La Comisión Nacional de la Verdad incorporó en el Volumen II de su informe los estudios realizados sobre los pueblos indígenas y las violaciones de derechos humanos durante la dictadura. Dada la complejidad y la falta de pesquisas, no es posible enumerar en este textos los múltiples tipos de violaciones que los pueblos indígenas sufrieron.

Fueron emitidas muchas declaraciones fraudulentas que certificaban la inexistencia de indios en las áreas apetecidas por particulares. Para tomar posesión de esas áreas y volver real la extinción de los indios en el papel, empresas y particulares promovieron tentativas de extinción física de pueblos indígenas enteros -lo que configura un genocidio tercerizado- que llegaron a valerse de la oferta de alimentos envenenados, contagios premeditados, secuestros de niños, así como de masacres con armas de fuego [...] la introducción deliberada de viruela, gripe, tuberculosis y sarampión entre los indios (CNV, Vol. II, 2014a: 206).

Se evidencia, por tanto, una participación específica del Estado en contra de los pueblos indígenas: primero, a través del Servicio de Protección a los Indios (SPI, 1910-1967), y posteriormente, a través de la Fundación Nacional del Indio (FUNAI, 1976 - hasta hoy), dos instituciones que, en sí mismas albergan muchas contradicciones. De manera breve, podemos decir que fueron creadas para atender las necesidades de los pueblos indígenas, pero se convirtieron en facilitadoras para que distintos agentes violaran los derechos humanos de los pueblos indígenas.

Como ocurrió en el caso de la construcción de la carretera BR-174, la FUNAI sirvió como puerta de entrada para la ejecución de otros proyectos en las reservas indígenas, facilitando los intereses privados en detrimento de los intereses de los pueblos indígenas. Esta obra derivó en más asesinatos y en la reducción de los territorios del pueblo Waimiri-Atroari. "La BR-174 fue concluida en 1979. En 1981, el gobierno federal incluyó la construcción de la central hidroeléctrica de Balbina y, por tanto, el general Figueiredo dividió la parte oriental de la Tierra indígena Waimiri-Atroari por medio del decreto no. 86.630"

(CNV, Vol. II, 2014a:235). 
Durante el mismo período de la construcción de la central hidroeléctrica, que implicó la remoción forzada de al menos dos aldeas, algunas compañías mineras consiguieron autorización para la prospección de minerales en la Tierra Indígena Waimiri-Atroari: “Con el decreto de Figueiredo, las empresas mineras Timbó/Parapanema y Taboca se pudieron establecer en un área de 526.80o hectáreas dentro de la reserva Waimiri-Atroari" (CNV, Vol. II, 2014a:236). Para ingresar al área, la minera Panapanema contrató una empresa paramilitar llamada Sacopã, especializada en 'limpiar la selva'. Se trataba de un equipo autorizado por el "Comando Militar de la Amazonia para 'mantener a su servicio 400 hombres equipados con armas 20 milímetros, rifle 38, revólveres de variado calibre y perros amaestrados”'. Se sumó a ello la invasión de las tierras por "colonizadores y terratenientes quienes se instalaban sobre las márgenes de la carretera BR-174 y al sur de la reserva" (Ibid). Las informaciones sobre estos y otros tipos de violaciones fueron ofrecidas a la CNV gracias al trabajo de las comisiones y comités organizados alrededor de la problemática indígena.

El Volumen II es una parte del informe que se compone de nueve Textos Temáticos producidos por los comisionados/as o consejeros/as de los Grupos de Trabajo que se estructuraron al interior de la CNV. Cabe resaltar que los temas presentados en ese Volumen son aquellos que ganaron espacio en el debate público dentro del rol de Comités y Comisiones que surgieron durante 2012, por medio de iniciativas de movimientos sociales, grupos de investigación de algunas Universidades, investigadores/as o miembros de la Comisión Nacional de la Verdad. Entre dichos temas, figuran "Dictadura y Homosexualidades"; "Civiles que colaboraron con la dictadura"; "Violaciones de derechos humanos de los pueblos indígenas", etc.

En lo referido a violaciones de derechos humanos de los pueblos del campo, los textos fueron elaborados bajo la responsabilidad de la comisionada María Rita Kehl. En esta parte del informe es posible notar la cooperación de los informes producidos sobre los indígenas y también por la Comisión Campesina de la Verdad: están claras las afinidades existentes entre el Volumen II de la CNV y el informe producido por la CCV. Se observa que ambas parten de la misma comprensión teórica: existía un plan político-económico de la dictadura para el campo brasileño, que tenía como principio el genocidio de los pueblos indígenas (Wilke, 2012; CEMVJ-AM, 2014; Valente, 2017). Por lo tanto, no se trata de una acción puntual, sino de un proyecto político fundamental para las demandas del capital en aquel momento.

A diferencia de lo que nos presenta el Volumen I del informe de la Comisión Nacional de la Verdad, existe una diversidad de tipos de violaciones que son asignadas a diversos agentes y situaciones, concediéndole un carácter multifacético al Estado como violador de derechos humanos. En el Volumen II, por ejemplo, fueron considerados como victimarios agentes de la iniciativa privada y la Unión Democrática Ruralista (UDR), que durante el año 1988 pasó a organizar de forma sistemática la violencia en el campo en casi la totalidad de los estados del país, promoviendo asesinatos de campesinos, sindicalistas, abogados, entre otros interesados por las cuestiones de esos pueblos, denominados en el informe como "Terrorismo Patronal". También consideró los muertos y desaparecidos en caso de disputas de tierra, haciendo énfasis en "la participación directa o indirecta (acción/omisión) de agentes del Estado" (CNV, Vol. II, 2014a). Otros tipos de violaciones consideradas fueron:

[...] disputas localizadas de poseiros ${ }^{20}$ vs. grileiros ${ }^{21}$, con participación agentes del Estado en defensa de los grileiros o en otros conflictos localizados por la tierra; abusos y violencias contra trabajadores autorizados a cultivar huertas dentro de grandes propiedades rurales, casos de violencia en respuesta a demandas por justicia laboral (CNV, Vol. II, 2014a:95-96).

\footnotetext{
20 N. de T.: Poseiros refiere a personas que ocupan tierras municipales o abandonadas, para cultivarlas.

21 N. de T.: Grileiros remite a personas que falsifican documentos para apropiarse de tierras municipales o ya ocupadas por alguna población. Ese proceso va acompañado de muchas acciones violentas.
} 
Vale mencionar que, de acuerdo con este Volumen del Informe, los tipos de violaciones mencionados no son entendidos como "graves violaciones". Apenas son citados para fines de comprensión del conflicto, del cual surgieron muchas organizaciones de lucha por los derechos laborales. Es este contexto, observamos que:

[...] múltiples asesinatos en el campo fueron en respuestas, por parte de los propietarios rurales, a simples reivindicaciones legales de sus empleados. La impunidad de los asesinos, incluso en los casos en que testimonios los denunciaban, indica la complicidad del poder local con los grandes propietarios de tierras (CNV, Vol. II, 2014a: 96).

Así como en el caso de los pueblos indígenas, las violaciones de derechos humanos ocurrieron a partir de grandes proyectos del gobierno federal, violando derechos de campesinos que ya vivían en las regiones, promoviendo la "expulsión de ocupantes [...] sin reparación ni derechos, y empleando "torturas y muertes de campesinos que resistiera a las expulsiones" (CNV, Vol. II, 2014a:96). Igualmente se registra la represión a los sindicatos de trabajadores rurales y a los movimientos de lucha por la reforma agraria, con asesinatos de líderes sindicales y políticos. Entre los crímenes citados en el Informe, se registra también el "reclutamiento de campesinos sin-tierra para el trabajo esclavo, con complicidad de autoridades locales" (2014a:96).

Observando los dos primeros volúmenes del informe de la CNV, se tiene la idea de que el Volumen I es oficial, validado por toda la Comisión, mientras que el Volumen II se trata de algo autónomo, de responsabilidad individual de los/as comisionados/as de cada Grupo de trabajo. Esta división puede apreciarse, por ejemplo, a partir de los tipos de violaciones que los instrumentos de justicia transicional brasileña han considerado, y que fueron tipificadas, y utilizadas, por la Comisión Especial de Muertos y Desaparecidos Políticos y por la Comisión de Amnistía. Por lo tanto, en estas Comisiones fueron predominantes los tipos de violaciones explicitados en el Volumen I, mientras que los demás tipos de violaciones relacionados con los pueblos del campo, que no caben en la estructura jurídico-conceptual, se encuentran registrados en el Volumen II. Esto nos puede ayudar a comprender el significado del conflicto relacionado con el número de víctimas de la dictadura, de las cualificaciones de algunas víctimas como Muertos y Desaparecidos, y el por qué de otras tantas que no fueron consideradas en esos términos.

$\mathrm{Al}$ igual que los campesinos, los pueblos indígenas, al involucrarse en la lucha por Memoria, Verdad y Justicia, interpelaron este campo de disputas, señalando la necesidad de construcción de otras formas de reparación, no exclusivamente restringidas a la reparación individual económica, sino a una reparación colectiva vinculada al modo de reproducción de sus vidas en sus distintas cosmologías.

Observamos que, durante la actuación de la CNV, estas contradicciones aparecieron en la forma de contabilizar Muertos y Desaparecidos, en la concepción de víctima, en el tipo de agentes violadores y en sus violaciones. Estas categorías fueron forjadas, en un amplio proceso de disputa, por los diferentes sujetos involucrados en este escenario. En el caso de los pueblos del campo, estas contradicciones también tienen sus raíces en la "cuestión agraria" brasileña. Al parecer, los conceptos que orientaron a la Comisión Nacional no contemplaron esas otras posibles violaciones.

Así, se evidencia la necesidad de reinterpretar las normas de derechos humanos y sus conceptos, como la conceptualización de "graves violaciones de derechos humanos", toa vez que la realidad de las violaciones sufridas por los Pueblos del Campo, como fue expuesto, exigía que dicha definición fuera ampliada. 


\section{A modo de conclusión}

Los éxitos en las medidas designadas por la justicia transicional y otras respuestas a las graves violaciones de derechos humanos, de modo general, guardan fuerte relación con la adhesión o no de los países a los tratados internacionales, y especialmente, con las luchas sociales sostenidas internamente (Brito et al, 2004). En el caso de Brasil, las acciones de los pueblos del campo en esa disputa dejaron en evidencia otros matices de los límites de la Justicia Transicional.

La entrega del informe final de la Comisión Nacional de la Verdad y la expectativa en torno de su publicación, y la de otros informes de comisiones de la verdad, hicieron emerger muchas contradicciones expresadas en las lecturas efectuadas por los/as militantes por el derechos a la Memoria, a la Verdad y a la Justicia de los pueblos del campo, es decir, el contenido del informe de la CNV, las recomendaciones, la disposición de los temas en el cuerpo del propio informe y las configuraciones conceptuales.

En aquel momento, fue posible observar disputas que giraron en torno de la estructura conceptual y normativa de los instrumentos legales ya constituidos, enfocando los criterios de reconocimiento de las víctimas, la estandarización de tipos de víctimas y perpetradores, y los tipos de violaciones. En este sentido, los pueblos del campo enfrentaron muchos obstáculos para su reconocimiento, dado que aquello que estaba establecido en las experiencias anteriores de políticas de memoria no abarcaba las formas de violaciones y de víctimas en las distintas realidades de los pueblos del campo. Observamos que la construcción de esas políticas y la forma cómo son orientadas, las someten a una política de orden global y nacional. Además, esas contradicciones están situadas en la posición de clase y de cultura de los grupos sociales, pasando también por el filtro de la comprensión política individual y por las relaciones entre los diferentes sujetos que están vinculados a la lucha por Memoria, Verdad y Justicia.

Recibido: 30 de octubre de 2017

Aprobado: 10 de marzo de 2018

Revisión: Federico Lavezzo

* Esta investigación está siendo financiada por el CNPQ.

\section{Referencias bibliográficas}

AGENCIA BRASIL On line. 2014. Fórum legislativo debate relatório da CNV sobre direitos humanos na ditadura. Disponível en:< http:/|agenciabrasil.ebc.com.br/direitos-humanos/noticia/2014-12/forum-legislativodebate-relatorio-da-cnv-sobre-direitos-humanos-na>. Recuperado el 30 de marzo de 2016.

BRASIL. Lei № 12.528 de 18 de novembro de 2011. Cria a Comissão Nacional da Verdade no âmbito da Casa Civil da Presidência da República. Disponible en: <http:/|www.planalto.gov.br/ccivil_03/_ato2011-2014/2011/lei/ l12528.htm>. Recuperado el 20 de diciembre de 2017

BRITO, A. B.; GONZÁLEZ-ENRIQUEZ, C.; FERNÁNDEZ, P. A. (Coord.). Política da memória: verdade e justiça na transição para a democracia. Lisboa: ICS, 2004. (Estudos e Investigações 35)

CANABARRO, Ivo. 2014. "Caminhos da Comissão Nacional da Verdade (CNV): memórias em construção". Revista Sequência (Florianópolis), 69: 215-234, dez.

CANUTO, A; SILVA LUZ, C. R. da; PINTO ANDRADE, T. V. (coords). 2015. Conflitos no campo - Brasil. Goiânia: CPT Nacional. 
CARNEIRO, A.; CIOCCARI, M. 2011. Retrato da Repressão Política no Campo Brasil 1962-1985. Camponeses torturados, mortos e desaparecidos. 2o edição. Brasília: Ministério do Desenvolvimento Agrário.

Carta dos Comitês. 2012. Disponible en: <https://comitedaverdadeportoalegre.wordpress.com/2012/08/13/ carta-dos-comites-a-comissao-nacional-da-verdade/>. Recuperado el 10 de octubre de 2016.

Comissão de Familiares de Mortos e Desaparecidos Políticos. 2009. Dossiê Ditadura: mortos e desaparecidos políticos no Brasil - 1964-1985. São Paulo: Imprensa Oficial.

Comissão Nacional da Verdade (CNV). 2014.a. Relatório, Volume I. Brasília: CNV.

Comissão Nacional da Verdade (CNV). 2014b. Relatório, Volume II - Textos Temáticos. Brasília: CNV.

COMISSÃO Nacional da Verdade no Brasil, Resolução no 5 de 2012. Disponível em: <http:/|www2.planalto. gov.br/>. Acesso em: 17 nov. 2014.

Comissão Camponesa da Verdade (CCV). 2014. Relatório. Disponible en: <https://cpdoc.fgv.br/sites/default/ files/Relatório Final Comissão Camponesa da Verdade - ogdez2014.pdf〉. Recuperado el 12 de marzo de 2015

DECLARAÇÃo do Encontro Nacional Unitário de Trabalhadores e trabalhadoras, povos do campo das águas e das florestas. 2012. Disponible en:<http:/|www.reformaagrariaemdados.org.br/sites/default/files| Declara\%C3\%A7ao_do_Encontro_Nacional_Unitario_2012.pdf > . Recuperado el 15 de junio de 2018 International Center for Transitional Justice (ICTJ) On line. What is Transitional Justice. Disponible en: https://www.ictj.org/about/transitional-justice. Recuperado el 20 de abril de 2017.

LEFRANC, Sandrine; MOURALIS, Guillaume. 2014. "De quel(s) droit(s) la justice internationaleest-elle faite?” Socio, 3: 209-245. Disponible em: http://socio.revues.org. Recuperado el 20 de abril de 2018. PINTO, Simone Rodrigues. 2010. "Direito À Memória e À Verdade: Comissões de Verdade na América Latina”. Revista Debates, Porto Alegre, 4(1): 128-143, jan./jun.

PEREIRA, Bruna Ferrari. 2016. Comissão Nacional da Verdade: limites e desafios. Dissertação de mestrado, Programa de Pós Graduação em Ciência Política da Universidade Federal de São Carlos.

PEREIRA, Mateus Henrique de Faria. 2015. "Nova direita? Guerras de memória em tempos de Comissão da Verdade (2012-2014)". Varia Historia, Belo Horizonte, 31(57): 863-902, set/dez.

SCHINKE, Vanessa Dorneles. 2016. "Relatório da Comissão Nacional da Verdade: o discurso sobre o judiciário". Revista Direito e Práxis, Rio de Janeiro, 7(14): 291-316.

SAUER, Sérgio; SARAIVA, Regina C.F. (Re)construção da memória de repressão e resistências camponesas: Reflexões sobre a Comissão Camponesa da Verdade. MRo7 - Conflitos e repressão aos trabalhadores rurais e urbanos no regime militar no Brasil. 39 Encontro Nacional da ANPOCS, 2015, Caxambú. In: Anais..., Caxambu, 2015. Disponível em: <https://www.anpocs.com/index.php/39-encontro . Recuperado el 05 de octubre de 2016.

SCHWADE, Egydio. 2011. "Os índios se opunham ao processo de invasão de seu território, no Amazonas, imposto pelos militares". Disponible: https://www.cartacapital.com.br/politica/2000-waimiri-atroaridesaparecidos-na-ditadura . Recuperado el 15 de enero de 2018.

TEITEL, Ruti. 2003. “Transitional Justice Genealogy”. Harvard Human Rights Journal, 16. Cambridge. Genealogía de la Justicia Transicional, Centro de Derechos Humanos, Facultad de Derecho, Universidad de Chile. Disponible en 〈http://www.cdh.uchile.cl/media/publicaciones/pdf/18/59.pdf $>$. Recuperado el 15 de octubre de 2016

TELES, Janaína (org.). 2001. Mortos e desaparecidos políticos: reparação ou impunidade? 2. ed. São Paulo: Humanitas/FFLCH-USP.

VALENTE, Rubens. 2017. Os Fuzis e as flechas; história de sangue e resistência indígena na ditadura. São Paulo: Companhia das Letras. 
VIANA, Gilney Amorim. 2013. Camponeses mortos e desaparecidos : excluídos da justiça de transição. Brasília, DF: Secretaria de Direitos Humanos da Presidência da República.

WEICHERT, Marlon Alberto. 2011. "A Sentença da Corte Interamericana de Direitos Humanos e a obrigação de instituir uma Comissão da Verdade." In: Luiz Flavi Gomes \& Valerio de Oliveira Mazzuoli (orgs.), Crimes da ditadura militar: uma análise à luz da jurisprudência atual da Corte Interamericana de Direitos Humanos. São Paulo: Editora Revista dos Tribunais. 226-242

WELCH, Clifford Andrew. 2014. “Camponeses, a verdade e a História da ditadura em São Paulo”. Revista Mundos do Trabalho, 6(11): 57-78.

WILKE, Maurício de Lima. 2012. Yanomami. "Denúncia de Maurício de Lima Wilke, 2012. Carta à Comissão Nacional da Verdade". Disponible en <https:||namo2.safelinks.protection.outlook.com/?url=http\%3A\%2F\%2Fwww.docvirt.com\%2Fdocreader.net\%2Fdocreader.aspx\%3Fbib\%3DComissaoVerdade\%26pesq\%3D\%26pesquisa\%3DPesquisar\&data $=02 \% 7$ Co1\%7C\%7C 9193 bcboed6d 4 fa35a3bo8d 5479 ca9af\%7C84dfge7fegf640afb435aaaaaaaaaaaa\%7C1\%7Co\%7C636493660605031233\&sdata=BisCPPhY9g7f2ay\%2FwS1WUVZMPxLRLfb\%2FD9XzndytKFw\%3D\&reserved=0>. Recuperado el 20 de noviembre de 2017.

\author{
Adriana Rodrigues Novais \\ Universidad Estadual de Campinas \\ https://orcid.org/oooo-0001-7559-5668 \\ E-mail:drinovais@yahoo.com.br
}

